\title{
Analysis Of Service Demand of Low Temperature Logistics Based on Kano Model-An Example of Sfbest Company
}

\author{
Meichiao Lai ${ }^{1, ~ *}$, Junyan Guo \\ ${ }^{1}$ Department of Logistics Management, Fuzhou University of International Studies and Trade, \\ Fuzhou, China 350202 \\ ${ }^{2}$ Fuzhou University of International Studies and Trade, Fuzhou, China 350202 \\ *2477580978@qq.com,936208640@qq.com
}

Keywords: Service Quality, Service Demand, Low Temperature Logistics, KANO model, Demand Classification

Abstract: With the rapid development of China's economy, the living standards of the people have been increasing day by day, people's life rhythm has accelerated, and consumption patterns have also changed. The convenience of the Internet has prompted more and more people to start purchasing some necessities such as daily necessities, frozen products, vegetables and fruits, and dairy products through the Internet. This also promotes the rapid development of China's cold chain logistics industry. Cold chain logistics is different from general logistics. In the distribution process, cold chain logistics pay more attention to maintaining the temperature of goods and the quality of goods. This article takes Sfbest Company as the object, uses KANO model to design questionnaires and conducts network survey to collect data, analyzes consumer service needs, from seven aspects of personnel contact, information management, order processing, distribution procedures, warehousing, environment and management mechanism. Investigate the demand for Sfbest Company low-temperature logistics service to clarify the factors affecting the demand of low-temperature logistics services. The results obtained provide suggestions for the feasibility of Sfbest Company, which is intended to improve the service quality of Sfbest Company low-temperature logistics.

\section{Introduction}

With the rapid development of advanced technology, China's economic level has rapidly jumped, and the development of the national economy has brought about the development of industry, agriculture and enterprises. Also, due to the continuous changes in people's consumption concepts in recent years, consumption habits have also changed, and online ordering has become the mainstream of consumption. The convenience of online shopping has made people choose online shopping, and the demand for seafood, aquatic products, dairy products, vegetables and fruits on the Internet is increasing. In order to enable people to eat fresh food, some domestic logistics companies began to provide low-temperature logistics and distribution, and promote the 
development of cold chain logistics. According to the data of the 2016 China E-Commerce Market Data Monitoring Report, the total amount of e-commerce transactions in China in 2016 was 22.97 trillion Yuan, a year-on-year increase of 25.5\%.Among them, the transaction volume of the online retail market was 5.3 trillion Yuan, a year-on-year increase of 39.1\%. In 2016, the total transaction volume of China's fresh e-commerce business was 91.3 billion Yuan, an increase of $80 \%$ over the 54.2 billion Yuan in 2015. It is estimated that the overall market size in 2017 will reach 150 billion Yuan. In recent years, the development of cold chain logistics on the economic support level has developed from the early stage of development to the middle stage, but there are still many problems in the process of development. Among them, the relatively important is the lowtemperature logistics distribution process, and the logistics technology and logistics equipment are relatively backward compared with other countries. Therefore, this study uses Sfbest Company as the research object, analyzes the service demand of consumers through questionnaire survey, clarifies the influencing factors of Sfbest Company low-temperature logistics distribution service demand, and provides optimization strategies accordingly.

\section{Literature Review}

\subsection{Factors affecting the quality of cold chain logistics services}

Ju-Chia Kuo and Mu-Chen Chen (2010) believe that in the management of cold chain logistics, although temperature monitoring requires higher costs, it plays a vital role in food quality and safety, so through the establishment of joint distribution The multi-temperature zone distribution system can reduce the cost of cold chain logistics on the one hand, and can also monitor the temperature well on the other hand (Kuo\&Chen, 2010). Vass.MD (2006) proposes that if the temperatu2010s improperly controlled in cold chain logistics, it will lead to the quality and safety of fresh products. Through the hazard analysis and key control point system, combined with temperature monitoring technology, the key hazards in cold chain logistics can be obtained. Point and control and improve it.

Yan Zhou (2009) mentioned the important role indicators affecting the quality control of cold chain logistics in the research of cold chain logistics quality control, including personnel, technical equipment, operation, mechanism and environment of cold chain logistics. The establishment and application of the indicator system can be used as a basis for evaluating the quality control level of cold chain logistics, ensuring the effectiveness of the cold chain logistics quality control system, thereby ensuring food safety and improving the service quality of cold chain logistics.

Judith Kreyenschmidt (2010) designed an effective temperature control detection system for improving food quality. He believes that meeting the optimal temperature of the product is a prerequisite for ensuring the quality of food cold chain logistics services. Becker \& Porter (2007) conducted a detailed analysis of the factors affecting food safety, and found that an effective way to reduce the unsafe probability of food and improve the quality of cold chain logistics services is to build and improve the food safety early warning system. Salin \& Nayage (2003) analyzed the food cold chain logistics in many developing countries: the cold chain service outsourcing is one of the effective ways to improve the quality of service in the food cold chain process. From the perspective of consumers. Mentzer (2001) analyzed consumers in detail to determine the dimensions of logistics service quality, and through quantitative methods, the three factors that affect service quality are time, environment, and availability.

Foreign research on logistics service quality theory has been 40 years old, mainly from two aspects to study the evaluation of logistics service quality. First, in logistics enterprises, Perreault and Russ (1974) proposed 7Rs theory based on time and place utility. The theory constructs 7 indicators: the correct rate of goods, the integrity of goods, the accurate information of goods, the punctuality of delivery, the accuracy of delivery of goods, time and price. Grnoros and Parasuraman 
et al. (1984, 1985) successively established service quality models. Secondly, based on the customer's perspective to evaluate the quality of logistics services. Mentz, etc. (1989) believed that logistics service quality includes customer service quality and delivery service quality. The main content of logistics service quality includes delivery time and goods. The state, the service personnel's handling of errors, etc., constitute the measurement indicators of the quality of the distribution logistics service.

\subsection{Related research on KANO model}

The KANO model is a tool model created by Noriaki Kano, a professor at Tokyo Institute of Technology, to prioritize customer demand classifications. This model is used to analyze customer needs based on the impact of customer satisfaction. According to the relationship between different types of quality characteristics and customer satisfaction, Professor Kano has divided the quality characteristics of product services into the following five categories:

\subsubsection{Must demand (M)}

Regarding to the attributes or functions that the customer "must have" for the products provided by the enterprise. The provider provides them with no satisfaction, but if not, the customer is not satisfied.

\subsubsection{One-Dimensional demand $(0)$}

The more such demand is provided, the greater the customer satisfaction will be; conversely, the less the demand is provided, the more the customer's dissatisfaction will increase.

\subsubsection{Attractive demand (A)}

If the company does not meet the customer's needs, the customer will not feel dissatisfied; once provided, the customer's satisfaction will rise accordingly.

\subsubsection{In-differential requirements (I)}

No impact on the user experience, whether provided by the enterprise or not.

\subsubsection{Reverse demand ( $R$ )}

After the enterprise provides, the user satisfaction will decrease, and the degree of supply is inversely proportional to the degree of user satisfaction (Kano. 1984).

\section{Research Method}

This study uses consumers of Sfbest Company as the research object, collects the data through online questionnaire survey, and then uses the KANO model to analyze the data of collected questionnaires, so as to obtain the customer's demand for Sfbest Company low-temperature distribution service. The questionnaire was distributed from November 15th to December 5th, 2017. A total of 177 valid questionnaires were collected and the effective recovery rate was $100 \%$.

The content of the questionnaire is divided into seven dimensions and twenty-six indicators. The seven dimensions are personnel contact, information management, distribution procedures, technical equipment, warehousing, environment and management mechanisms; they include a total of 26 indicators. The KANO model questionnaire is different from other questionnaires, and each 
question is asked in two forms: when it is available and when it is not. For example, when SF prefers to have or does not have this service, how does it feel to the users? There are specific scores when they are available and when they are not available. The scale are divided into 5 points, in terms of very satisfied, of course, no feeling, acceptable and dissatisfied, as shown in Table 1 below.

Table 1 Item form of questionnaire for KANO model

\begin{tabular}{|c|c|c|c|c|c|}
\hline Question & Satisfied & Of course & No feeling & Acceptable & $\begin{array}{l}\text { Un } \\
\text { satisfied }\end{array}$ \\
\hline When available & 5 & 4 & 3 & 2 & 1 \\
\hline When not available & 5 & 4 & 3 & 2 & 1 \\
\hline
\end{tabular}

The collected questionnaire first converts each questionnaire through the interpretation of the above table, and then accumulates the times of various quality requirements in a counting manner. The majority rule is adopted, and the most demanding item is the demand category of the factor. Among them, A means for "Attractive quality", I is for "Indifference quality", R represents for "Reverse quality", M stands for "Must quality", and O stands for "One-dimensional quality (Matzler, Hinterhuber., 1996). The KANO two-dimensional model evaluation table is shown in Table 2 below:

Table 2 KANO Evaluation Form

\begin{tabular}{|c|c|c|c|c|c|}
\hline \multirow{2}{*}{ When available } & \multicolumn{5}{|c|}{ When not available } \\
\cline { 2 - 6 } & Satis fied & Of course & No feelings & Acceptable & Unsatisfied \\
\hline Satisfied & $\mathrm{Q}$ & $\mathrm{A}$ & $\mathrm{A}$ & $\mathrm{A}$ & $\mathrm{O}$ \\
\hline Of course & $\mathrm{R}$ & $\mathrm{I}$ & $\mathrm{I}$ & $\mathrm{I}$ & $\mathrm{M}$ \\
\hline No feeling & $\mathrm{R}$ & $\mathrm{I}$ & $\mathrm{I}$ & $\mathrm{I}$ & $\mathrm{M}$ \\
\hline Acceptable & $\mathrm{R}$ & $\mathrm{I}$ & $\mathrm{I}$ & $\mathrm{I}$ & $\mathrm{M}$ \\
\hline Unsatisfied & $\mathrm{R}$ & $\mathrm{R}$ & $\mathrm{R}$ & $\mathrm{R}$ & $\mathrm{Q}$ \\
\hline
\end{tabular}

\section{Analysis results of the questionnaire}

\subsection{Reliability of the questionnaire}

This paper uses SPSS 22.0 statistical software to analyze the reliability of the collected questionnaires. Table 3 shows the results of the reliability analysis of the questionnaire. It can be seen that the questionnaire of this study is credible.

Table 3 Results of reliability analysis

\begin{tabular}{|c|c|}
\hline Dimension & Cronbach's Alpha value \\
\hline Personnel contact & 0.619 \\
\hline Information management & 0.754 \\
\hline Delivery procedure & 0.818 \\
\hline Technical equipment & 0.787 \\
\hline Warehousing & 0.587 \\
\hline Environmental aspects & 0.513 \\
\hline Management mechanism & 0.584 \\
\hline
\end{tabular}




\subsection{Sample analysis}

There were 63 males in the sample of this study, accounting for 35.59\%; 114 females, accounting for $64.41 \%$ of the total. It can be known that women use SF Express to prefer low temperature logistics services more than men. The age group of 21-30 years old is mainly used by $\mathrm{SF}$, accounting for $48.59 \%$ of the total number of questionnaires; the age of $31-40$ years is $24.29 \%$, and the age group of 51-60 years old and 61 years old is relatively small. In terms of occupation, the proportion of employees, office workers, and administrative institutions is relatively high. Nowadays, the competition in the society is getting more and more fierce. Office workers and administrative institutions have relatively no leisure time to shop, and most of them choose to buy online, which is convenient and saves time. The number of students who use Sfbest Company is the most preferred, most of them buy dairy products, and many of them help to buy fresh food at home.

\subsection{Classification of KANO quality attributes}

The KANO quality requirement attribute classification uses the principles of relatively large number, and 26 service elements are classified into five quality attributes. The results are shown in Table 4 below.

Table 4 Quality attribute classification table

\begin{tabular}{|c|c|c|c|c|c|c|c|c|}
\hline \multirow[t]{2}{*}{ Dimension } & $\begin{array}{c}\text { Quality } \\
\text { attribute }\end{array}$ & Q & A & $\mathrm{O}$ & I & M & $\mathrm{R}$ & \multirow{2}{*}{$\mid \begin{array}{c}\text { Classificati } \\
\text { on }\end{array}$} \\
\hline & Question & \multicolumn{6}{|c|}{ Quantity } & \\
\hline \multirow{3}{*}{ Personnel contact } & 1 & 14 & 41 & 71 & 33 & 18 & 0 & $\mathrm{O}$ \\
\hline & 2 & 12 & 50 & 43 & 38 & 34 & 0 & A \\
\hline & 3 & 12 & 55 & 44 & 42 & 24 & 0 & A \\
\hline \multirow{4}{*}{$\begin{array}{l}\text { Information } \\
\text { management }\end{array}$} & 4 & 12 & 54 & 48 & 36 & 27 & 0 & A \\
\hline & 5 & 12 & 28 & 79 & 27 & 31 & 0 & $\mathrm{O}$ \\
\hline & 6 & 12 & 49 & 35 & 27 & 54 & 0 & $\mathrm{M}$ \\
\hline & 7 & 12 & 44 & 55 & 32 & 33 & 1 & $\mathrm{O}$ \\
\hline \multirow{5}{*}{ Delivery procedure } & 8 & 13 & 37 & 38 & 28 & 61 & 0 & M \\
\hline & 9 & 13 & 46 & 49 & 42 & 27 & 0 & $\mathrm{O}$ \\
\hline & 10 & 11 & 48 & 42 & 53 & 23 & 0 & I \\
\hline & 11 & 11 & 40 & 29 & 32 & 65 & 0 & M \\
\hline & 12 & 11 & 40 & 59 & 38 & 29 & 0 & $\mathrm{O}$ \\
\hline \multirow{5}{*}{$\begin{array}{l}\text { Technical } \\
\text { equipment }\end{array}$} & 13 & 11 & 38 & 63 & 42 & 23 & 0 & $\mathrm{O}$ \\
\hline & 14 & 13 & 40 & 60 & 39 & 25 & 0 & $\mathrm{O}$ \\
\hline & 15 & 13 & 36 & 58 & 43 & 27 & 0 & $\mathrm{O}$ \\
\hline & 16 & 12 & 28 & 23 & 34 & 79 & 1 & M \\
\hline & 17 & 11 & 39 & 64 & 31 & 31 & 1 & $\mathrm{O}$ \\
\hline \multirow{3}{*}{ Warehousing } & 18 & 11 & 37 & 56 & 40 & 32 & 1 & $\mathrm{O}$ \\
\hline & 19 & 11 & 50 & 38 & 45 & 33 & 0 & A \\
\hline & 20 & 11 & 47 & 20 & 48 & 51 & 0 & M \\
\hline \multirow{3}{*}{$\begin{array}{l}\text { Environmental } \\
\text { aspects }\end{array}$} & 21 & 11 & 28 & 28 & 73 & 17 & 15 & $\mathrm{O}$ \\
\hline & 22 & 12 & 46 & 45 & 52 & 20 & 2 & I \\
\hline & 23 & 11 & 39 & 56 & 33 & 37 & 1 & $\mathrm{O}$ \\
\hline \multirow{3}{*}{$\begin{array}{l}\text { Management } \\
\text { mechanism }\end{array}$} & 24 & 11 & 42 & 43 & 48 & 31 & 2 & I \\
\hline & 25 & 11 & 38 & 47 & 52 & 29 & 0 & I \\
\hline & 26 & 11 & 42 & 37 & 27 & 59 & 1 & $\mathrm{M}$ \\
\hline
\end{tabular}




\section{Conclusions and recommendations}

\subsection{Conclusion}

According to the analysis results, there are 12 service requirements belonging to the onedimensional quality, which are the timely response of the service personnel, the confidentiality of the transaction data, the delayed delivery of the goods and timely notification to the consignee, the sanitary cleaning status, the correctness of the order processing, and the distribution of goods. Good temperature maintenance, suitability of logistics equipment, applicability of temperature control equipment, suitability of testing equipment, advanced temperature control technology, good storage temperature of goods, humidity deviation of low temperature logistics, etc. These service items indicate that the better the service provided by the industry, the more satisfied the consumer is, but if the service is not good, the consumer is not satisfied, so the providers and operators need to spend more time trying to make the consumer more satisfied. Therefore, providers must invest most resources to develop and maintain a high level of service in this area.

There are 6 service requirements that are essential qualities, which are to notify consumers in time the status of ordered goods, no damage during the delivery process, the accuracy of the delivery time of goods, advanced preservation technology, quantity of goods to meet consumer demand, low temperature logistics related, the perfection of the management mechanism, these indicators are the most important and most basic services for consumers. If they are provided, the customers will not be satisfied, however, If they are not provided, the customers will be dissatisfied, so if the providers do not pay attention to the services of these indicators, they will lose a large number of consumers.

There are four service requirements for the attractive quality, the skill level of the service personnel, the professional knowledge of the service personnel, the easy-to-understand information about the products, and the good packaging of the products. These items indicate that the consumers seem to pay less attention, but If the provider has made an effort, it will certainly be able to add a lot of points in the minds of consumers, however, it can't be paid too much. If it is not the same as the perception of consumers, it will cause waste of resource costs.

There are 4 service requirements for in-differential quality, such as handling efficiency, convenient transportation, packaging materials comply with green concept, and provide waste recycling. These projects are less important and less preferred than other services, although Consumers don't pay much attention to it, but if you think about it with sufficient resources, it may improve consumer perception and attract new consumers. It is a set of indicators with great potential, as summarized in Table 5 below.

Table 5 Classification results of 26 service demand

\begin{tabular}{|l|l|}
\hline Quality attribute & \multicolumn{1}{|c|}{ Item } \\
\hline One-dimensional quality & Questions:1,5,7,9,12,13,14,15,17,18,21,23 \\
\hline Must quality & Questions:6,8,11,16,20,26 \\
\hline Attractive quality & Questions:2,3,4,19 \\
\hline In-difference quality & Questions:10,22,24,25 \\
\hline
\end{tabular}

\subsection{Suggestion}

According to the research results, the service requirements of 26 items are classified, and the following suggestions are proposed for Sfbest Company low-temperature logistics distribution service according to its importance. 


\subsubsection{Update of Information system security and product information}

Through the analysis results, it is found that the confidentiality of transaction data is an important indicator. Sfbest Company is obliged to protect the privacy of consumers from being leaked. In addition, delays in delivery of goods and timely notification to the consignee, and the correctness of order processing are all one-dimensional quality. If Sfbest Company is offered more, the more happy the consumer will be: on the contrary, the less provided, the more disappointing the consumer will be, so that a linear relationship is presented. Therefore, the protection of commodity information and the timely updating of commodity information Sfbest Company need to be optimized to make customers more assured and satisfied.

\subsubsection{To strengthen the quality control of all aspects of low-temperature logistics}

There is no damage during the delivery process, and the accuracy of the delivery time is a musthave quality. Sfbest Company should ensure that the goods are delivered to the consumer in a complete manner. The delivery time of goods is very important for every company. Therefore, Sfbest Company to improve the service on the basis of the original. If the goods are not delivered on time, the consumer should be notified in time and the reason should be given to give the consumer a satisfactory answer. The good condition of the merchandise delivery temperature is also a one-dimensional quality. The merchandise is taken out from the dispatcher to the consumer. During this time, the temperature of the merchandise will change due to the change of the external temperature. This is the last one in the distribution process. Steps, Sfbest Company should improve the quality of service in this area.

\subsubsection{Personnel should be trained}

In the conclusion, the timely response of service personnel is a one-dimensional quality, which is necessary for Sfbest Company service quality. Therefore, the service attitude is first, carefully answering doubts for the guests, and ensuring that the consumers' doubts can be solved in the shortest time to improve efficiency. The skill level of the service personnel, the professional knowledge of the service personnel for the goods, and the good packaging of the goods are provided. "The three items are classified as attractive quality. If Sfbest Company prefers to train the service personnel, the professional knowledge and skills of the service personnel will be improved. The mind must be able to add a lot of points, which is a service demand that can provide a competitive advantage for Sfbest Company.

\subsubsection{Investment in updating low temperature logistics technology equipment}

Through the analysis of the results, it is concluded that the suitability of logistics equipment, the applicability of temperature control equipment, the applicability of testing equipment and advanced temperature control technology belong to the one-dimensional quality. Since the temperature control of the low-temperature logistics is very strict, Sfbest Company to focus on these items. By investing in updating the low-temperature logistics equipment and personnel temperature control technology to ensure the quality of the products, consumers can buy satisfactory products. Thereby enhancing Sfbest Company brand image.

\subsubsection{Focus on green logistics}

Through the analysis of the results, it is known that the packaging materials conform to the green concept and provide waste recycling with no difference in quality. Indifference quality means that Sfbest Company not to invest too much resources in this area, but as long as Sfbest Company pay 
attention to this area, consumers will feel satisfied. In addition, green environmental protection is the trend now day. It is everyone's responsibility to protect the environment. If Sfbest Company is better to be greener in the first step, it can improve the competitive advantage of Sfbest Company in the industry and contribute to the sustainable development of Sfbest Company.

\subsection{Limitations and prospects of the research}

This research is based on the example of Sfbest Company, and the service demand attribute is understood through the survey of consumers. However, due to limited data, the research results may not be classified. Subsequent researchers can expand the research object, through a large number of data analysis, and can take into account various factors such as cost and benefit, a more comprehensive analysis of low-temperature logistics service needs, for the development of China's low-temperature logistics to make greater contribution.

\section{References}

[1] Becker G S, Porter D V., 2007. The federal food safety system: A primer. Congressional Research Service, Library of Congress.

[2] Granroos C. A., 1984. Service Quality Model and Its Marketing Implications. European Journal of Marketing, 1984(4), pp.36-44.

[3] Ju-Chia Kuo, Mu-Chen Chen. 2010. Developing an advanced Multi-Temperature Joint Distribution System for the food cold chain. Food Control, 21(4), pp. 559-566.

[4] Judith Kreyenschmidt., 2010. A novel photochromic time-temperature indicator to support cold chain management. International Journal of Food Science and Technology. 45, pp.208-215.

[5] Kano N E A., 1984. Attractive quality and must-be quality. The Journal of Japanese Society for Quality Control, 2(41), pp. 39-48.

[6] Kurt Matzler, Hans H. Hinterhuber., 1996. How to delight your customers. Journal of Product \& Brand Management. 5(2), pp. 6-18.

[7] Mentzer J T, Gomes R, Krapfel R E., 1989. Physical distribution service: A fundamental marketing concept. Journal of the Academy of Marketing Science. 17(4), pp.53-62

[8] Neil Vass. M.D., 2006.Tracking weakest links in cold chain. Master Thesis of University of California Press.

[9] Parasuraman A, Zeithaml V A, Berry L I., 1985. A Conceptual Model of Service Quality and Its Implications for Future Research. Journal of Marketing, (3), pp.41-50.

[10] Perreault W D, Russ F A., 1974. Physical Distribution Service: A Neglected Aspect of Marketing Management. Msu Business Topics, (Summer), pp.37-45.

[11] Victoria Salin, Rodolfo M.Nayage Jr., 2003. A cold chain network for food export to developing countries. International Journal of physical Distribution \& Logistics Management. 33(10), pp.918-933

[12] Yan Zhou., 2009. Research on quality control of cold chain logistics. Dissertation of Lanzhou University of Technology. 
Table 6 The 26 service demands of 7 Dimensions

\begin{tabular}{|c|c|c|}
\hline No. & Dimensions & Questions \\
\hline 1 & Personnel contact & $\begin{array}{ll}\text { 1. } & \text { The timely response of service personnel } \\
\text { 2. } & \text { The skill level of the service personnel } \\
\text { 3. } & \text { Service personnel's expertise in commodities }\end{array}$ \\
\hline 2 & Information management & $\begin{array}{l}\text { 4. Consumers are easy to understand about product } \\
\text { information } \\
\text { 6. Confidentiality of transaction data } \\
\text { Notify consumers in time to order the status of the } \\
\text { 7. The goods are delayed and the consignee's arrival } \\
\text { time is notified in time. }\end{array}$ \\
\hline 3 & Delivery procedure & $\begin{array}{ll}\text { 8. } & \text { Accuracy of goods delivery time } \\
\text { 9. } & \text { Order classification processing correctness } \\
\text { 10. Loading and unloading, handling effectiveness } \\
\text { 11. There is no damage during the delivery of goods } \\
\text { 12. The product distribution temperature is maintained } \\
\text { in good condition. }\end{array}$ \\
\hline 4 & Technical equipment & $\begin{array}{ll}\text { 13. } & \text { Logistics equipment applicability } \\
\text { 14. } & \text { Temperature control equipment suitability } \\
\text { 15. } & \text { Testing equipment suitability } \\
\text { 16. } & \text { Advanced preservation technology } \\
\text { 17. } & \text { Advanced temperature control technology } \\
\end{array}$ \\
\hline 5 & Warehousing & $\begin{array}{l}\text { 18. The product storage temperature is maintained in } \\
\text { good condition. } \\
\text { 19. Provide good packaging for goods } \\
\text { 20. Meet the needs of consumers in terms of the } \\
\text { quantity of goods }\end{array}$ \\
\hline 6 & Environmental aspects & $\begin{array}{l}\text { 21. The humidity of the low temperature stream is not } \\
\text { biased } \\
\text { 22. Convenience of transportation } \\
\text { 23. Sanitary cleaning status }\end{array}$ \\
\hline 7 & Management mechanism & $\begin{array}{l}\text { 24. Packaging materials conform to the green concept } \\
\text { 25. Provide waste recycling } \\
\text { 26. The perfection of the management mechanism } \\
\text { related to low temperature logistics. }\end{array}$ \\
\hline
\end{tabular}

